\title{
Research on Water Resistance of The Hanging Wall of the Fault Tilting Water- resisting Key Strata Model
}

\author{
Wang Yuhe $^{1}$ Zhang xinglei $^{2}$ Wang Houchen ${ }^{2}$ Cheng Jiulong ${ }^{1,3}$ Guo Wei ${ }^{1}$
}

${ }^{1}$ Key Laboratory of Mine Disaster Prevention and Control Shandong University of
Science and Technology Qingdao 266590,China
${ }^{2}$ Shandong Xinwen Mining Company Xintai 271202,China
${ }^{3}$ State Key Laboratory of Coal Resources and Safe Mining China University of
Mining and Technology Beijing 100083,China

Abstract: In order to make inrush coefficient method more accurate and effective in the coal floor water bursting evaluation, taking into account the interaction between the mine floor and the fault under the influence of mining, establishing the model of hanging wall tilting resisting key strata, solving the deflection of the sheet model under the action of the overburden rock stratum and confined water. The reasonable of the model was analyzed through numerical simulation software FLAC3D, the results showed that: the hanging wall sloping impermeable layer model key was reasonable in the water inrush evaluation of the mine floor near the fault.

Key words: water inrush from mine floor; water inrush coefficient method; impermeable key layer; mechanical analysis; numerical simulation

\section{Introduction}

In recent years, although mine production technology has been greatly improved with the coal mining deepening of theoretical research, but the coal mine water inrush is still frequent. A lot of coal resources could not be exploited which caused by serious water bursting and complex hydrogeological conditions. Currently the national coal mine reserves suffered water damage threatened exceed 250 million tons, which mainly distributed in about $70 \%$ of national output in North China, East China, South China and other industrialized areas. Large number of statistical results showed that the vast majority of water inrush and fault accidents are directly related to water inrush, over $90 \%$ of water inrush accident occurred in the fault zone itself and its neighboring range, which accounted for $74 \%$, water inrush was less frequent cases in the full floor ${ }^{[1]}$. Water inrush coefficient method ${ }^{[2]}$ as the widespread used of coal mining floor water damage degree evaluation formula is weak in fault structures containing face floor due to the effective confining layer thickness is difficult to determine. In this I researched complex hydrogeological conditions of water inrush danger conduct and considered about the various controlling factors of the water inrush and fault, established the key hanging wall sloping impermeable layer and the rationality of the model was simulated analysis in order to verify its legitimacy, and thus provided an important reference for the inrush of water near the fault face evaluation. 


\section{2. evaluation formula of water inrush coefficient method}

Water inrush coefficient method commonly was used to evaluate the harm degree of floor water in coal mining of China, this method is derived from the statistic analysis, the long-term practice of water inrush data of regularity, and as the basic provisions included in the specification and mine water prevention and control regulations. It can be calculated as follows:

$T_{S}=p /\left(\mathrm{m}_{0}-C_{p}\right)=p /\left(\sum M_{i} m_{i}-C_{p}\right.$

Where $p$ is the value of hydraulic pressure ( $M P a)$ and $m_{0}$ is the equivalent thickness of water-resisting layer (m) and $C_{p}$ is the mine pressure of destroyed floor depth (m), $M_{i}$ is the true thickness of water-resisting layer bottom layer $(\mathrm{m}), m_{i}$ is the stratified equivalent thickness conversion formula.

\section{Establishment of Key Hanging Wall} tilting Impermeable Layer[3-5] Model

When the method of coefficient of water bursting is applied to working face floor near fault, it does not take into account the effect of the fault affected by mining. In fact useful thickness of watertight stratum of working face floor near fault will inevitably affected by the fault. In order to study the effect of the fault to the useful thickness of watertight stratum, first of all establish the mechanical model of water resistance of the hanging wall of the fault.

The graph one is the schematic diagram of mining face containing the fault by using strike longwall coal mining method with a fault dipping angle of alpha. After coal mining, the area of stress concentration (support pressure zone) and stress reduced area (distressed zone) is formed in surrounding rock of working face causing stope wall rock damage. For the coal floor, it formed water flowing fractured zone. The fault activation confined water may upflow for fault zones and fault plane due to the confined water, and the influence of mining stress occur certain displacement. When coal floor mining water flowing fractured zone spilled into the fault water flowing fractured zone depth lead water fracture zones, the working face floor water inrush

occurs; When coal floor mining water flowing fractured zone depth is not affected by the fault water flowing fractured zone, at this point in the coal floor mining water flowing fractured zone and the fault water flowing fractured zone exist between remaining intact rock mass, if the remaining intact rock mass can resist the role of the confined water, it will not occur face water inrush, vice fault inrush.

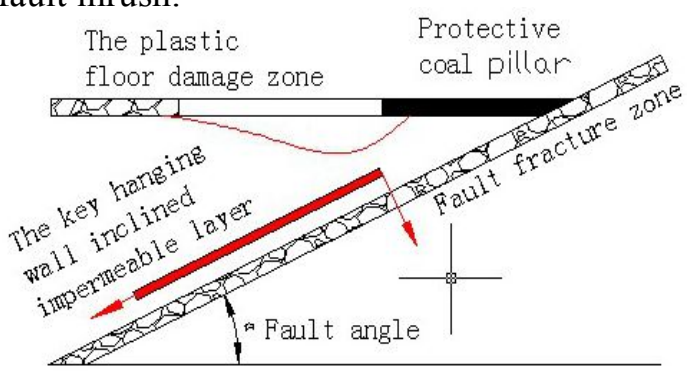

Fig.1 Schematic diagram of hanging wall tilting resisting key strata

In order to study the effects of working face mining for fault, after the mining face, in addition to mining coal floor damage depth, in the floor mining damage zone (water flowing fractured zone) and fault lead water fracture zones 
exist between the intact rock band (fault hanging wall tilt water blocking tapes).

\subsection{Failure Characteristics of Mechanical Analysis Seam Floor}

To analyses the key aquifuge in the tilt floor which is on the fault's hanging wall with mechanics, and the key aquifuge mechanics model is set up as shown in figure 2 , the thickness of $h_{\text {key }}$ is less than the thickness of the remaining intact rock mass the load of the Overlying Strata which is on the protective pillar's inferior rock is not only no reduction but also appear stress concentration in some part, so the minimum principal stress in rock mass will not reduce, its water preventing ability is stronger. So the tilt key aquifuge's right from standing fault protection coal pillar, the direction of the key aquifuge's overlying load is vertical downward. Set up as shown in figure 2 (a) coordinate system ( $Z$ direction perpendicular to the tilt key aquifuge downward) the tilt key aquifuge with completed clamped supported whose body force to $\mathrm{F}$, length in the $\mathrm{X}$ direction is $a$, in the $\mathrm{Y}$ direction length is $\mathrm{b}$, and the horizontal contained angle is alpha. Analyses the tilt key aquifuge's profile which is along the $\mathrm{Y}$ direction, as shown in figure 2 (b), without considering The caving zone of stapes roof influence on the tilt key aquifuge,look the tilt key aquifuge's Overlying Strata as load q (Y) whose direction is vertical downward toward the surface of the tilt key aquifuge (as shown in figure 2 (b) due to the tilt of key aquifuge, the load on the Overlying Strata is non-uniform loading.);look Confined Water in fault as the hydraulic load $\mathrm{p}$ (y) which effect perpendicular to the tilt key aquifuge's under face, due to the hydraulic load is grads load, the gradient of hydraulic load is proportional to the altitude of the tilt key aquifuge, as shown in figure 2 (b).Due to the direction of the load which effect on the tilt key aquifuge's upper surface is vertical downward (the horizontal contained angle is alpha.) we want to deal with the problems with the convenient method, so we decomposed $\mathrm{q}$ (y) into $\mathrm{q}_{1}$ and $\mathrm{q}_{2}$, the direction of $\mathrm{q}_{1}$ is perpendicular to the tilt key aquifuge, an the direction

of $q_{2}$ is parallel to the tilt key aquifuge along the y direction tilting downward as shown in figure 2 (c), Considering the tilt key aquifuge's body force, decomposed $F$ into $F_{1}$ and $F_{2}$, and the direction of $F_{1}$ and $F_{2}$ is same to $q_{1}$ and $q_{2}$.due to the direction $\mathrm{q}(\mathrm{y})$

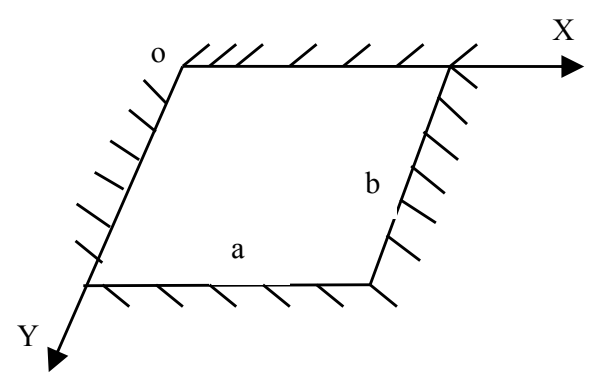

(a)

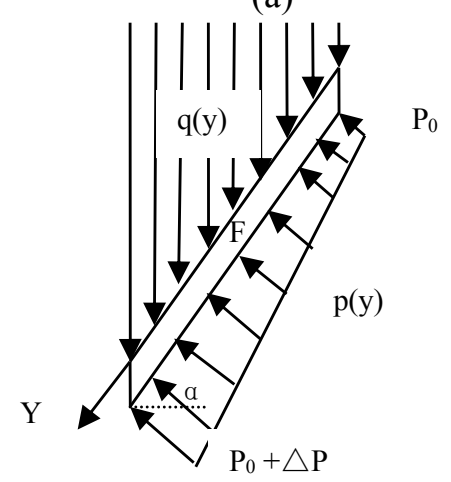

(b) 


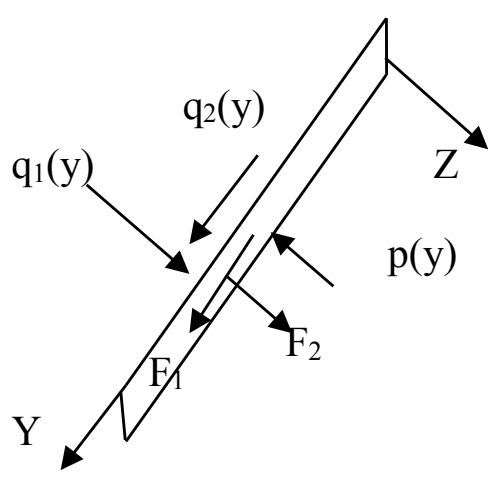

(c)

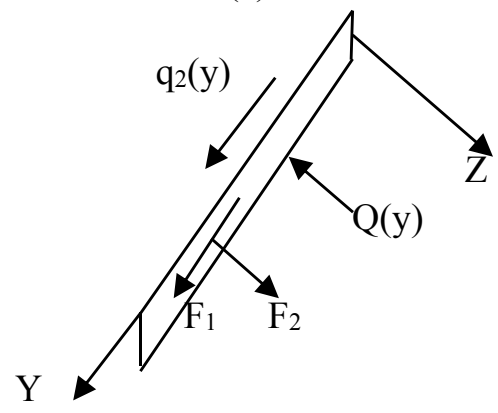

(d)

Fig.2 Mechanical model of hanging wall tilting resisting key strata

is perpendicular to the tilt key aquifuge,so look it as the lateral load . the relation between the lateral load and the longitudinal load as shown in (2) - (10).

$$
q_{0}=\rho_{\mathrm{r}} g L_{0} \tan \alpha
$$

Where $q_{0}$ is the force on the top plate and $L_{0}$ is the length of the fault waterproof pillar and $g$ is the gravitational coefficient.

$$
\Delta p=\rho_{w} g b \sin \alpha
$$

Where $\Delta p$ is the confined water difference between the up and down of the plate boundary along the $\mathrm{Y}$ direction and $\rho_{w}$ is the density of confined water and $b$ is the length of the taken model along the Y-direction.

$$
\Delta q=\rho_{r} g b \sin \alpha
$$

Where $\Delta q$ is the pressure difference between the the upper boundaries taken from up and down of the model along the $\mathrm{Y}$ direction and $\rho_{r}$ is an average density of impermeable layer.

$$
\mathrm{q}(y)=q_{0}+\frac{\Delta q}{b} y
$$

where $\mathrm{q}(y)$ is the linear pressure value of the model in the $\mathrm{Y}$ direction.

$$
\mathrm{p}(y)=p_{0}+\frac{\Delta p}{b} y
$$

Where $\mathrm{p}(y)$ is the water pressure value of the model in the $\mathrm{Y}$ direction.

$q_{1}(y)=q(y) \cos \alpha$

Where $q_{1}(y)$ is the vertical stress of the model in the $\mathrm{Z}$ direction.

$$
q_{2}(y)=q(y) \sin \alpha
$$

Where $q_{2}(y)$ is the tangential stress of the model along the $\mathrm{Y}$-axis direction.

$F_{1}=F \sin \alpha$

$F_{2}=F \cos \alpha$

Where $F$ is physical strength of the model and $F_{1}$ is the physical strength component of the model along the Y-axis direction and $F_{2}$ is the physical strength component of the model along the Z-axis direction. 
3.2 Key Hanging Wall tilting Impermeable Layer Deflection Variational Method[6-7]Calculation

The analysis of hanging wall tilting impermeable layer critical shows that the forces acting on the sloping

impermeable layer on the critical lateral load in the $\mathrm{X}$ direction is unchanged, while in the $\mathrm{Y}$ direction is increased linearly (hanging wall inclination critical layer overlying impermeable load and load are confined water increases linearly distributed), select the form as formula (1) shown in the deflection function expression under the conditions of the key hanging wall tilting impermeable layer clamped boundary. Located in the longitudinal load and lateral load combined effects, this hanging wall sloping impermeable layer deflection function key can be calculated as follows: $w=\sum_{m=1}^{\infty} \sum_{n=1}^{\infty} a_{m n} y \sin ^{2}\left(\frac{m \pi x}{a}\right) \sin ^{2}\left(\frac{n \pi}{b}\right.$ (11)

By variational method elasticity obtained and in the combined effects of horizontal and vertical loads this key hanging wall tilting impermeable layer deflection function coefficients $a_{m n}$ of w can be calculated.

The resulting solution of $a_{m n}$ substituted into formula (11) which can be derived by solving Equation thin plate.

\section{Numerical simulation of seepage flow}

In order to study rationality of the key hanging wall sloping impermeable layer mechanical model, using FLAC $^{3 \mathrm{D}}$ software, seam floor and hanging wall sloping impermeable layer key stopes mining and confined water under the influence of the displacement of common rules for further coupling Numerical simulation analysis ${ }^{[8]}$.

Based on longwall mining and structural characteristics of the fault, the establishment of Figure 3 along the seam toward numerical simulation model. Model geometry size $380 \times 300 \times 220 \mathrm{~m}$, seam thickness of $5 \mathrm{~m}$, the model at the bottom of artesian water aquifer, which is impermeable upper critical layer thickness is $60 \mathrm{~m}$, normal faults drop is $25 \mathrm{~m}$, dip angle of $35^{\circ}$. Mining model using stepwise manner, each step forward $25 \mathrm{~m}$, once mining full height. Created with a certain thickness of the fault rupture zone for considering fault fracture zone of two measurements. Bottom of the model vertical displacement constraints, constraints on both sides of the horizontal displacement. Model overburden height of $100 \mathrm{~m}$, in order to form uniform load to load the model boundary, $\mathrm{q}=2.2 \mathrm{MPa}$. The bottom of the confined water aquifer pore Water pressure to a fixed value, $p=$ $3 \mathrm{MPa}$. Model of the physical and mechanical properties of the rock formations Table 1.1.

FLAC $^{3 \mathrm{D}}$ simulation model had a total of 299,320 units, 347,970 nodes. Numerical containing faults shown in Figure 3:In order to observe the hanging wall tilting impermeable layer displacement and its key coal mining floor with the relationship between displacement, establishing six observations in the model line, the observation to observation point line given in the form, with the various records stopes advance measuring the displacement measuring point line, displacement of coal seam floor furnished 
three survey lines were recorded for the line 1 , line 2 , line 3 . Which line 1 fault waterproof pillar in front observation point position is: $\mathrm{x}$-axis direction along the model, 140m, 150m, 160m, along the $\mathrm{y}$-axis direction 50-300m each survey line uniform six measuring points. along the $\mathrm{z}$-axis model a height of $40 \mathrm{~m}, 50 \mathrm{~m}, 60 \mathrm{~m}$. FLAC $^{3 \mathrm{D}}$ numerical simulation based on recorded vertical displacement of the measuring point data is shown in Figure 4

Table 1.1 Physical mechanical parameters of rock body

\begin{tabular}{|c|c|c|c|c|c|c|c|c|}
\hline strata & $\begin{array}{l}\text { density } \\
/ \mathrm{kg} \cdot \mathrm{m}^{-3}\end{array}$ & $\begin{array}{l}\text { Bulk } \\
\text { modulus/ } \\
\mathrm{GPa}\end{array}$ & $\begin{array}{l}\text { Shear } \\
\text { modulus/ } \\
\mathrm{GPa}\end{array}$ & $\begin{array}{l}\text { cohesion } \\
/ \mathrm{MPa}\end{array}$ & $\begin{array}{l}\text { Tensile } \\
\text { strength/ } \\
\mathrm{MPa}\end{array}$ & $\begin{array}{l}\text { Internal } \\
\text { friction } \\
\text { angle/ } \\
\left(\begin{array}{c}\circ \\
()\end{array}\right.\end{array}$ & $\begin{array}{l}\text { Permeabil } \\
\text { ity } / 10^{-} \\
{ }^{14} \mathrm{~ms}^{-1}\end{array}$ & porosity \\
\hline $\begin{array}{l}\text { Fault } \\
\text { fracture } \\
\text { zone }\end{array}$ & 1000 & 0.074 & 0.5 & 0 & 0 & 22 & 1500 & 0.35 \\
\hline siltstone & 2600 & 3.45 & 2.0 & 3.8 & 1.8 & 40 & 2.5 & 0.4 \\
\hline $\begin{array}{l}\text { Sandy } \\
\text { mudstone }\end{array}$ & 2450 & 3.83 & 2.41 & 3.5 & 1.5 & 38 & 2.8 & 0.45 \\
\hline gritstone & 2300 & 4.45 & 1.60 & 3.3 & 1.75 & 39 & 3.1 & 0.5 \\
\hline Aquifer & 3100 & 14.15 & 4.8 & 6.2 & 8.65 & 37.8 & $2.42 \mathrm{e}-5$ & 0.7 \\
\hline $\begin{array}{l}\text { Coal } \\
\text { seam }\end{array}$ & 1400 & 3.0 & 1.0 & 1.6 & 0.9 & 28 & 0.02 & 0.5 \\
\hline
\end{tabular}

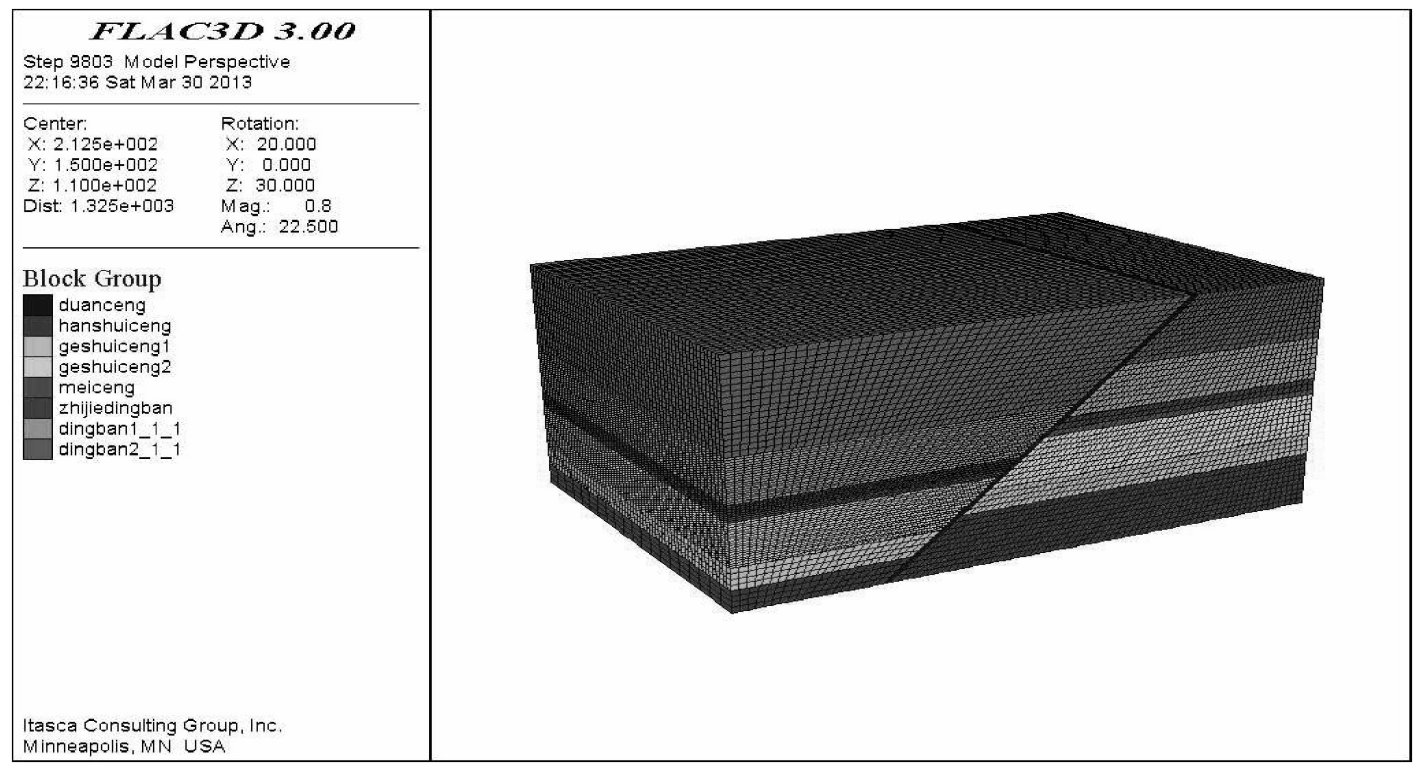

Fig.3 The model of numerical calculation

variation of the measuring line, conclusions:survey line 1 , survey line 2 , according to Figure 4 the following line 3 vertical displacement measured 
steady decline, survey line survey line 1 and 2 in the stopes advance to $96 \mathrm{~m}$, has begun to produce upward vertical displacement of the stopes advance to $108 \mathrm{~m}$ or so reached $-0.015 \mathrm{~m}$ and $-0.02 \mathrm{~m}$ and stabilized, the measured line 3 has been in a steady decline in the state in which maximum negative displacement$0.037 \mathrm{~m}$. Survey line survey line 1 and 2 Owing to the lower floor gob in confined water and under stress perturbations can see two lines are generated upward deflection, while measuring line 3 owing impermeable bottom boundary pillar Therefore it is not resulting in upward displacement.

Figure 5 with the stopes advance key hanging wall tilting impermeable layer along the z-direction displacement contours, it can be seen from the figure: the stopes advance to $28 \mathrm{~m}, 56 \mathrm{~m}, 84 \mathrm{~m}$ when the hanging wall tilting observation plane deflection gradually increases along the $\mathrm{z}$-axis negative direction, with the stopes gradually trending fault waterproof pillar forward, oval-shaped deflection along the tilting surface is also developed on the face, tilting critical layer impermeable face plate deflection and deflection is associated, in stopes advance to $112 \mathrm{~m}$, the slope z-direction displacement of $35 \mathrm{~m}-58 \mathrm{~m}$ range absolute value decreases, that is, the part is displaced along the z-axis, tilt base for gob direction, and between the $60 \mathrm{~m}-70 \mathrm{~m}$ did not produce significant shift perturbations due to the segment range at fault waterproof pillar below the fault waterproof pillar beneath rock barrier with the kick drum and the gob direction to the displacement.

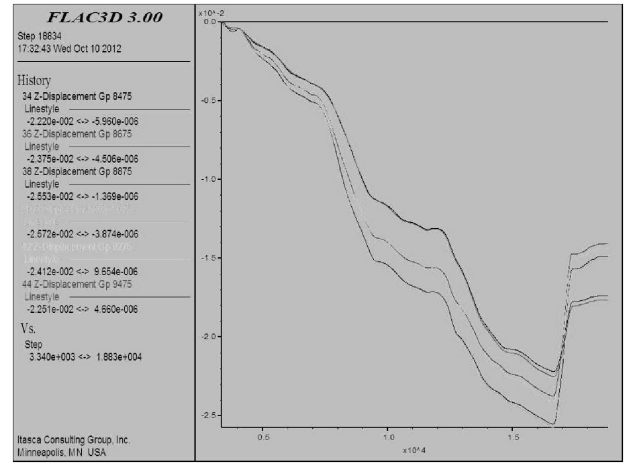

(a) Measuring line 1

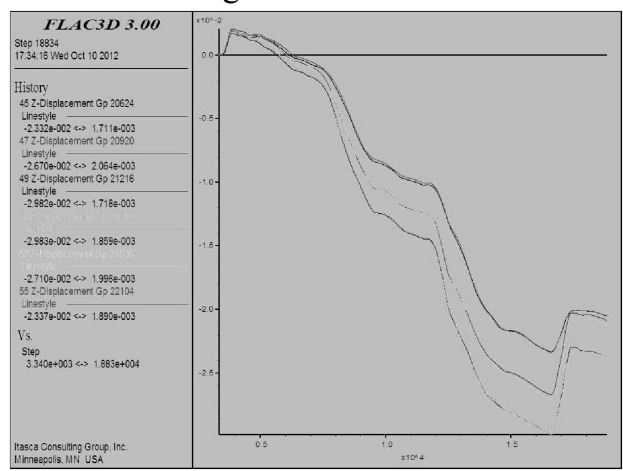

(b) Measuring line 2

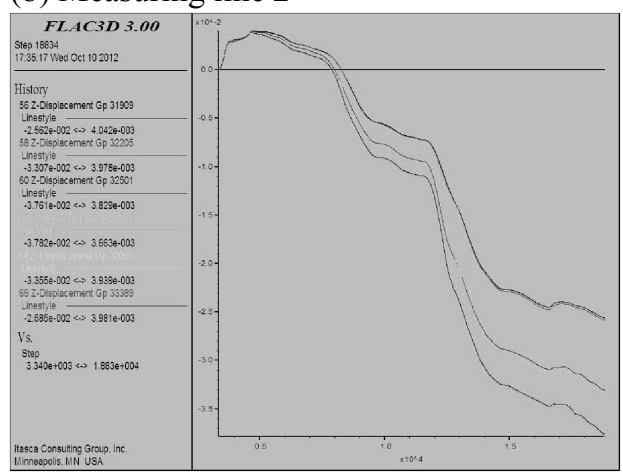

(c) Measuring line 3

Fig.4 The vertically displacement of observation spots of different lines with mining advancing 


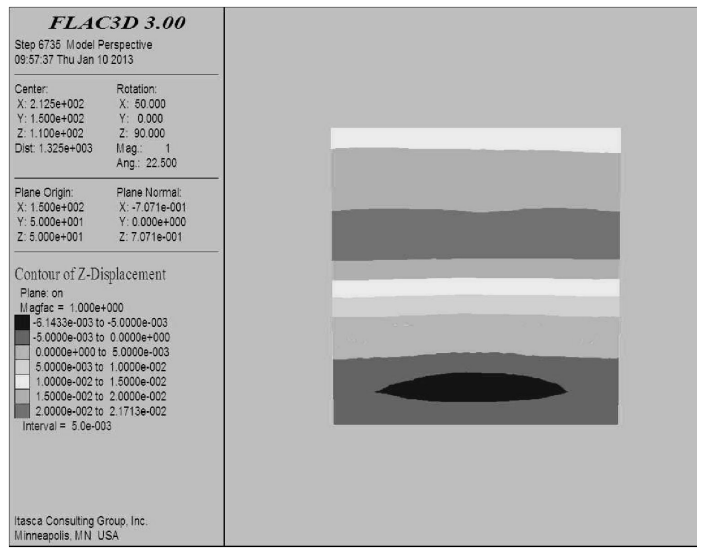

(a) Pushing $28 \mathrm{~m}$ stopes

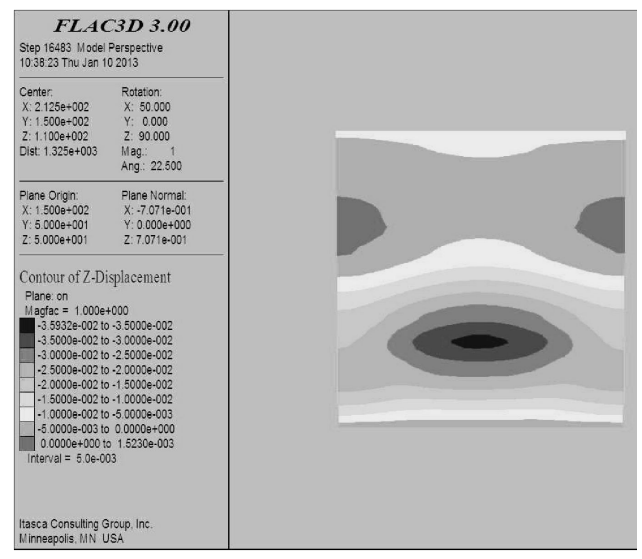

(b) Pushing $84 \mathrm{~m}$ stopes

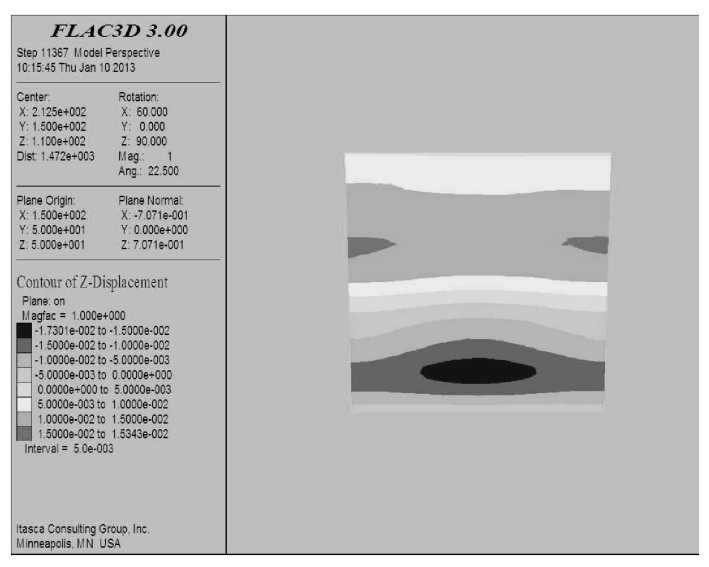

(c) Pushing 56m stopes

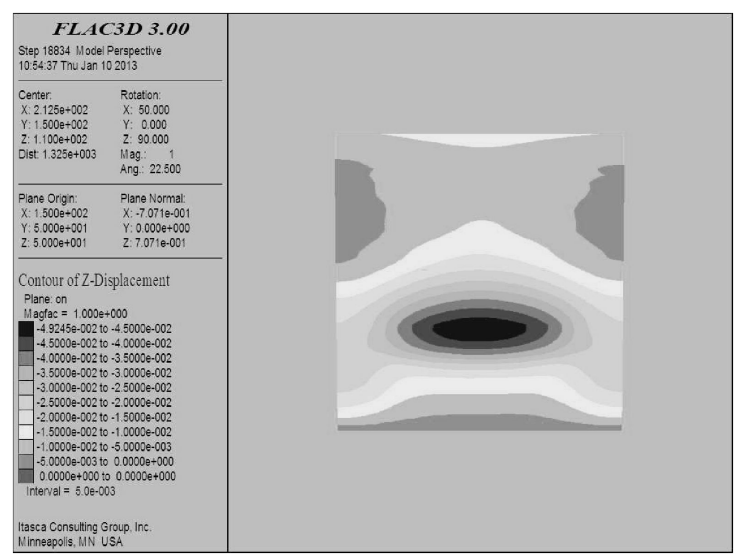

(d) Pushing $112 \mathrm{~m}$ stopes

Fig .5 The floor failure distribution during working face advanced

\section{Conclusions}

The key hanging wall tilting impermeable layer mechanical calculation mode was established by mechanical analysis near the fault rock, thinking about the hanging wall rock along the fault tilt direction affected by mining perspective. linearly increasing loads hanging wall tilting impermeable layer deflection function key was constructed according to the four sides of the rectangular plate clamped boundary conditions and load distribution and based on the principle of minimum potential energy, using variational method for solving the deflection function, the improvement of water inrush coefficient formula has practical significance.

\section{References}

[1] Li Liangjie; Qian Minggao;Li Shugang.Mechanism of Water-Inrush Through Fault[J].Journal Of China Coal Society,1996, 21(2):119-123.

[2]Guan En tai.Water Bursting Coefficient And Coalmine Flood Damage Control[J].Coal Engineering, 2011 (01).

[3] Bu Wankui.Research On Mechanical Mechanism Of Fault Activation And 
Water Inrush From Faults In Mining Floor[D].Doctoral dissertation of china university of mining and technology,2000. [4] Bai Haibo. Seepage Characteristics Of Top Stratum Of Ordoviciansystem And Its Application Study As Key Aquifuge[D]. Xuzhou: China University of Mining and Technology,2008.

[5] Li Liangjie; Qian Minggao;Wen Quan;Meng Yiping. Relationship Between The Stability Of Floor Strueture And Water-Inrush From Floor[J]. Journal Of China University Of Mining And Technology, 1995, 24(4):18-23.

[6] Wu Jialong.Elasticity[D]. Higher Education Press, 2010.

[7] Sun Jian. Failure Characteristics and Water-inrush Mechanism of an Inclined Coal Seam Floor[D]. Doctoral dissertation of china university of mining and technology,2011.

[8]Xie Wenbing,Chen Xiaoxiang,Zheng Baisheng. Numerical Simulation Of Mining Engineering[M]. China University Of Mining And Technology Press,2005. 